\title{
Contralateral Breast Symmetrisation in Immediate Prosthetic Breast Reconstruction after Unilateral Nipple-Sparing Mastectomy: The Tailored Reduction/Augmentation Mammaplasty
}

\author{
Marzia Salgarello ${ }^{1}$, Giuseppe Visconti ${ }^{1}$, Liliana Barone-Adesi ${ }^{1}$, Gianluca Franceschini ${ }^{2}$, \\ Riccardo Masetti ${ }^{2}$ \\ ${ }^{1}$ Department of Plastic and Reconstructive Surgery, ${ }^{2}$ Breast Unit, Catholic University of the Sacred Heart-University Hospital \\ "A. Gemelli", Rome, Italy
}

Background In the literature on nipple-sparing mastectomy (NSM) with one-stage immediate implant reconstruction, contralateral symmetrisation has drawn little attention, with many surgeons still performing standard cosmetic mammaplasty procedures. However, standard implant-based mammaplasty usually does not result in proper symmetry with the mastectomy side, especially regarding breast projection, overall shape, and volume distribution.

Methods We retrospectively reviewed 19 consecutive patients undergoing unilateral NSM with immediate prosthetic reconstruction and contralateral simultaneous symmetrisation by using the tailored reduction/augmentation mammaplasty technique between June 2012 and August 2013.

Results The average follow-up time was 13 months (range, 10-24 months). No major complications, such as infection, haematoma, and nipple-areola complex necrosis, were experienced. Conclusions Our experience suggests that simultaneous contralateral symmetrisation with tailored reduction/augmentation mammaplasty after unilateral immediate implant reconstruction after NSM facilitates durable and pleasant symmetric outcomes.

\section{Keywords Mastectomy / Mastectomy, subcutaneous / Breast implants / Mammaplasty}

Correspondence: Marzia Salgarello Department of Plastic and Reconstructive Surgery, Catholic University of the Sacred HeartUniversity Hospital "A. Gemelli", Via Massimi 101, Rome 00136, Italy Tel: +39-06-35454470 Fax: +39-06-35454470 E-mail:m.salgarello@mclink.it

The authors thank Antonia Conti, Medical Artist, for designing high-fidelity artwork.

No potential conflict of interest relevant to this article was reported.

Received: 1 Nov $2014 \bullet$ Revised: 11 Jan $2015 \bullet$ Accepted: 14 Jan 2015

plSSN: 2234-6163 • elSSN: 2234-6171 • http://dx.doi.org/10.5999/aps.2015.42.3.302 • Arch Plast Surg 2015;42:302-308

\section{INTRODUCTION}

The literature contains abundant studies on breast reconstruction techniques after nipple-sparing mastectomy (NSM) [1-3]. However, contralateral symmetrisation mammaplasty after unilateral NSM implant-based breast reconstruction has received little attention [4-6].

An implant with a larger volume than the removed conus is necessary to properly fill up the deflated breast envelope after NSM. Standard breast augmentation or augmentation/pexy performed contralaterally can often result in asymmetry, even if the implants used are smaller and shaped differently than those used on the reconstructed side. This occurs because the implantto-breast transition on the mastectomy side is different from that on the healthy side.

The purpose of this paper is to present the tailored reduction/ 
augmentation mammaplasty technique used to achieve simultaneous contralateral symmetrisation following immediate onestage implant reconstruction after unilateral NSM.

\section{METHODS}

\section{Patients and methods}

Between June 2012 and August 2013, 19 consecutive women underwent unilateral NSM with immediate prosthetic reconstruction to treat breast cancer, followed by contralateral symmetrisation with implants. NSM was restricted to oncologic patients who met the following inclusion criteria: tumour size $<5$ $\mathrm{cm}$, tumour $\geq 2 \mathrm{~cm}$ from the nipple-areola complex (NAC), no skin involvement or inflammatory breast cancer, clinically negative axillae or a negative frozen section of the sentinel node, a negative intraoperative frozen section of the tissue immediately beneath the nipple, and the patients' choice to undergo NSM instead of breast conservative surgery.

The mean age of the patients was 45.2 years old (range, 36-58 years old). Six patients were of normal weight (body mass index [BMI] range, $\left.18.5-24.9 \mathrm{~kg} / \mathrm{m}^{2}\right)$ and 13 were overweight (BMI range, $25-29.9 \mathrm{~kg} / \mathrm{m}^{2}$ ).
With the aid of sizers, hyper-projected (used on the NSM side) and low-projected (used on the contralateral side) anatomical silicone-gel textured implants were placed in the submuscular plane by dissecting the submuscular-subfascial pocket on the mastectomy side and the dual-plane pocket on the healthy side (Table 1) [7-9]. The submuscular-subfascial pocket is accessed from the upper lateral border of the pectoralis major muscle and is defined by the pectoralis major muscle and its overlying fascia (superficial pectoralis fascia) up to the inferior margin of the pectoralis major muscle and inferolaterally by the superficial pectoralis fascia and coracoacromial fascia [9].

The reconstructive and aesthetic outcomes were evaluated separately by a blinded group of plastic surgeons as well as by the attending surgeon using our standard evaluation method (Table 2). This assessment was based on clinical examinations and by reviewing clinical pictures of the breasts. The BREASTQ score was used to ascertain the patients' satisfaction.

\section{Surgical technique}

After completing the NSM implant reconstruction, the dualplane pocket was dissected on the healthy side through inferior hemi-periareolar access and the trans-parenchymal route. A low-

Table 1. Patients' features along with mastectomy specimen data, implants and tailored reduction/augmentation data

\begin{tabular}{|c|c|c|c|c|c|c|c|}
\hline $\begin{array}{l}\text { Ptosis grade (implant-to- } \\
\text { breast frame analysis after } \\
\text { implant placement) }\end{array}$ & $\begin{array}{l}\text { Breast } \\
\text { (cup- } \\
\text { age }[y r])\end{array}$ & TNM & $\begin{array}{l}\text { Preoperative } \\
\text { asymmetry }\end{array}$ & $\begin{array}{l}\text { NSM side } \\
\text { and } \\
\text { specimen } \\
\text { weight }(\mathrm{g})\end{array}$ & $\begin{array}{l}\text { Implant size } \\
\text { (mastectomy side) }\end{array}$ & $\begin{array}{l}\text { Controlateral } \\
\text { scar-tailored } \\
\text { reduction and } \\
\text { specimen weight }(\mathrm{g})\end{array}$ & $\begin{array}{l}\text { Controlateral } \\
\text { implant size }\end{array}$ \\
\hline $\begin{array}{l}\text { No ptosis (mainly only hyperprojected, } \\
\text { overall hyperprojected) }\end{array}$ & $\begin{array}{l}\mathrm{B}-46 \\
\mathrm{~A}-36\end{array}$ & $\begin{array}{l}\text { TisNOMO } \\
\text { T1NOMO }\end{array}$ & $\begin{array}{l}\text { No } \\
\text { No }\end{array}$ & $\begin{array}{l}\text { R } 270 \\
\text { L } 175\end{array}$ & $\begin{array}{l}\text { Silimed Nuance XH } 405 \\
\text { Natrelle } 410 \text { MX } 325\end{array}$ & $\begin{array}{l}\text { PA-base-18 } \\
\text { PA-base-15 }\end{array}$ & $\begin{array}{l}\text { Silimed Nuance } 195 \\
\text { Silimed Nuance } 220 \text { L0 }\end{array}$ \\
\hline $\begin{array}{l}\text { Grade } 1 \text { (usually slight hyperprojected, } \\
\text { slight wider and with excess skin in } \\
\text { the lower pole, overall slightly wider } \\
\text { in the lower pole) }\end{array}$ & $\begin{array}{l}C-50 \\
B-43 \\
C-46\end{array}$ & $\begin{array}{l}\text { TisNOMO } \\
\text { T2NOM0 } \\
\text { T1NOMO }\end{array}$ & $\begin{array}{l}\text { R sb } \\
L \text { sb } \\
L s b\end{array}$ & $\begin{array}{l}R 294 \\
L 220 \\
L 380\end{array}$ & $\begin{array}{l}\text { Silimed Nuance XH } 350 \\
\text { Silimed Nuance XH } 350 \\
\text { Silimed Nuance XH } 485\end{array}$ & $\begin{array}{l}\text { V-vertical-50 } \\
\text { V-vertical+base-30 } \\
\text { V-vertical-28 }\end{array}$ & $\begin{array}{l}\text { Silimed Nuance } 170 \text { LO } \\
\text { Silimed Nuance } 170 \text { LO } \\
\text { Natrelle 410ML } 170\end{array}$ \\
\hline $\begin{array}{l}\text { Grade } 2 \text { (usually hyperprojected, wider } \\
\text { and with excess skin inferolaterally, } \\
\text { overall wider in the lower pole) }\end{array}$ & $\begin{array}{l}\text { D-47 } \\
\text { C-44 } \\
\text { C-58 } \\
\text { B-46 } \\
\text { C-38 } \\
\text { D-42 } \\
\text { D-46 }\end{array}$ & $\begin{array}{l}\text { TisNOM0 } \\
\text { TisNOM0 } \\
\text { TisNOM0 } \\
\text { T2NOMO } \\
\text { TisNOMO } \\
\text { T2N2M0 } \\
\text { T1NOMO }\end{array}$ & $\begin{array}{l}R \text { sb } \\
R \text { sb } \\
R \text { sb } \\
L s b \\
\text { No } \\
\text { Lb } \\
R b\end{array}$ & $\begin{array}{l}\text { R } 405 \\
\text { R } 376 \\
\text { R } 302 \\
\text { R } 236 \\
\text { R } 380 \\
\text { L } 409 \\
\text { L } 450\end{array}$ & $\begin{array}{l}\text { Silimed Nuance XH } 350 \\
\text { Silimed Nuance XH } 350 \\
\text { Silimed Nuance XH } 485 \\
\text { Silimed Nuance XH } 405 \\
\text { Silimed Nuance Hi } 395 \\
\text { Silimed Nuance XH } 440 \\
\text { Natrelle } 410 \text { LX } 570\end{array}$ & $\begin{array}{l}\text { J scar-J+base-133 } \\
\text { J scar-J+base-155 } \\
\text { V-vertical+base-45 } \\
\text { J scar-J+base-60 } \\
\text { J scar-J-80 } \\
\text { J scar-J+base-125 } \\
\text { J scar-J+base+SLQ-120 }\end{array}$ & $\begin{array}{l}\text { Natrelle 410ML } 125 \\
\text { Natrelle 410ML } 170 \\
\text { Natrelle 410ML } 195 \\
\text { Natrelle 410ML } 195 \\
\text { Natrelle 410ML } 170 \\
\text { Silimed Nuance } 220 \text { L0 } \\
\text { Natrelle 410ML } 220\end{array}$ \\
\hline $\begin{array}{l}\text { Grade } 4 \text { (glandular ptosis) (variably } \\
\text { hyperprojected, wider and with } \\
\text { variable excess skin in the lower } \\
\text { pole, overall variably hyperprojected } \\
\text { and wider in all quadrants) }\end{array}$ & $\begin{array}{l}\text { B-44 } \\
\text { B-36 } \\
\text { A-53 } \\
\text { C-43 } \\
\text { B-48 } \\
\text { B-49 }\end{array}$ & $\begin{array}{l}\text { T1NOM0 } \\
\text { TisNOM0 } \\
\text { T2N2M0 } \\
\text { TisNOMO } \\
\text { T1NOMO } \\
\text { TisNOMO }\end{array}$ & $\begin{array}{c}\text { No } \\
L \text { sb } \\
\text { No } \\
\text { No } \\
L \text { bs } \\
\text { No-previous } \\
\text { inverted-TRM }\end{array}$ & $\begin{array}{l}285 \\
\text { L } 285 \\
R \quad 175 \\
\text { L } 307 \\
R 243 \\
\text { L } 250\end{array}$ & $\begin{array}{l}\text { Silimed Nuance XH } 405 \\
\text { Natrelle } 410 \text { FX } 360 \\
\text { Silimed Nuance XH } 350 \\
\text { Natrelle } 410 \text { MX } 370 \\
\text { Natrelle } 410 \text { MX } 445 \\
\text { Silimed Nuance XH } 405\end{array}$ & $\begin{array}{l}\text { V-vertical-50 } \\
\text { V-vertical+ILQ\&SLQ-45 } \\
\text { J scar-J-46 } \\
\text { V-vertical+base+ILQ-83 } \\
\text { V-vertical+base-100 } \\
\text { J scar-J-75 }\end{array}$ & $\begin{array}{l}\text { Natrelle 410ML } 170 \\
\text { Natrelle 410FL } 190 \\
\text { Natrelle 410ML } 170 \\
\text { Natrelle 410ML } 195 \\
\text { Natrelle 410ML } 195 \\
\text { Natrelle 410ML } 170\end{array}$ \\
\hline $\begin{array}{l}\text { Grade } 5 \text { (pseudoptosis) (slightly } \\
\text { hyperprojected, overall slightly } \\
\text { hyperprojected) }\end{array}$ & A-44 & TisNOMO & Lsb & L 178 & Natrelle 410 MX 325 & Base-11 & FL 190 \\
\hline
\end{tabular}


projected anatomical silicone-gel textured implant was placed with the goal of ensuring a symmetrical breast bases. The patient was then placed in a semi-sitting position to check for symmetry. After implant placement, implant-to-breast transition analysis was performed by evaluating four parameters: projection, width, excess skin, and overall shape. This was carried out in order to tailor the contralateral symmetrisation after the implant was placed.

In non-ptotic breasts, the central breast base was reduced and circumareolar skin resection with interlocking suture (CRIS) was performed according to the technique described by Ham- mond $[10,11]$.

Grade 1 and grade 2 ptotic breast cases were managed by vertical or J-scar breast reduction in order to correct the ptosis, to remove excess inferolateral breast tissue in the lower pole, and to match breast width. In these cases, projection was managed with central breast base reduction and CRIS.

Grade 4 (glandular ptosis) breast cases were managed according to the specific needs of each case. Since the excess breast tissue is not primarily displaced into the lower quadrants, as in ptotic breasts, but is instead distributed in all four quadrants, the tailored resection of both the inferolateral and superolateral

Table 2. Evaluation methods of the aesthetic outcome using clinical photographs of the patients. It is based of five different items with three Likert subscales

\begin{tabular}{|c|c|c|c|}
\hline Items/subscales & 0 & 1 & 2 \\
\hline Breast volume & Marked discrepancy with contralateral breast and/or & Moderate discrepancy with contralateral breast and/or & Symmetric \\
\hline Breast contour & Marked contour asymmetry & Moderate contour asymmetry & Symmetric \\
\hline Inframammary crease & Poorly defined & Demarcated but asymmetric & Demarcated and symmetric \\
\hline Breast projection & Marked discrepancy with contralateral side & Mild discrepancy with contralateral side & Symmetric \\
\hline Overall result & Poor, needing of further operations & Fair, needing of second little surgery & Good, definitive result \\
\hline
\end{tabular}

\section{Fig. 1. Tailored mammaplasty case: intraoperative sequence}

(A) Dual-plane augmentation mammaplasty was performed through a periareolar approach, placing an Allergan Natrelle (Allergan Inc., Irvine, CA, USA) 410ML $220 \mathrm{~mL}$ implant. The breast base (i.e., retroareolar breast tissue) was removed. The specimen size is shown. (B) In order to symmetrize the lateral pole fullness, the superolateral breast quadrant was also resected. The specimen size is shown on the breast. (C) J-scar breast reduction was also performed. Notice the submuscular breast implant at the bottom of the image as well as the signs of tailored parenchyma resections. (D) Circumareolar skin resection and interlocking suture was performed before closure.
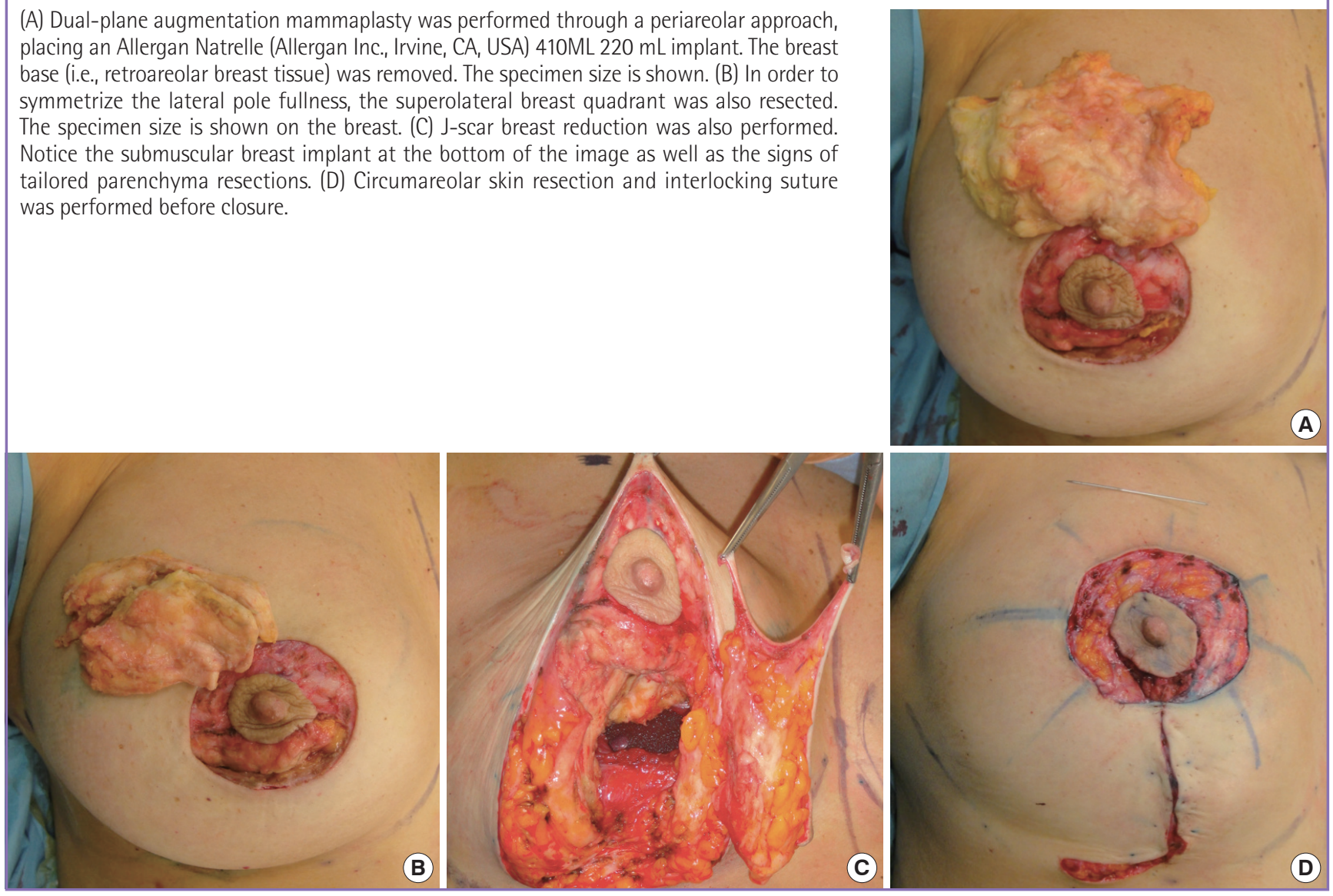
quadrants may be needed to match the overall breast shape, in addition to vertical or J-scar breast reduction. In our study, this took place in two cases.

Grade 5 (pseudoptosis) breast cases were managed as nonptotic breasts with smaller central breast base reduction and CRIS (Fig. 1).

Augmentation mammoplasty was performed first, followed by the tailored resection of the central breast base and, eventually, the tailored resection of the lateral quadrants. Through inferior periareolar access, the central portion of the gland was undermined from the pectoralis major muscle and a bevelled resection was performed in the planned direction. After the resection, the patient was again placed into a semi-sitting position to check for symmetry. Vertical or J-scar breast reduction was performed when needed, following resection patterns that were marked intraoperatively [12]. Since this surgical manoeuvre further influences breast projection and overall shape, the breast was basted with temporary stitches, and then projection and

\section{Fig. 2. Tailored mammaplasty along the breast transverse axis}

An artist's drawing illustrates the transverse axis of the right breast during one-stage immediate breast reconstruction after nipple-sparing mastectomy. Notice that the breast conus (parenchyma) is completely replaced by the definitive anatomic implant that provides the shape and projection of the reconstructed breast. The conical projection of the healthy breast is lost. The implant-to-breast transition is rough, consisting of the implant covered by the pectoralis major, a thin layer of subcutis, and skin. A smaller, low-projected implant has been placed in a dual-plane pocket to provide prosthetic imprinting to the contralateral breast. However, despite using the smallest implant possible, the augmentation mammaplasty alone cannot properly symmetrize the breast. The removal of the base of the breast (shown in pink), the resection of the lateral quadrants (shown in blue), and the removal of the circumareolar skin (shown in green) are the steps of tailored reduction designed to properly symmetrize the breast by flattening the breast and nipple-areola complex and symmetrizing the base of the breast.

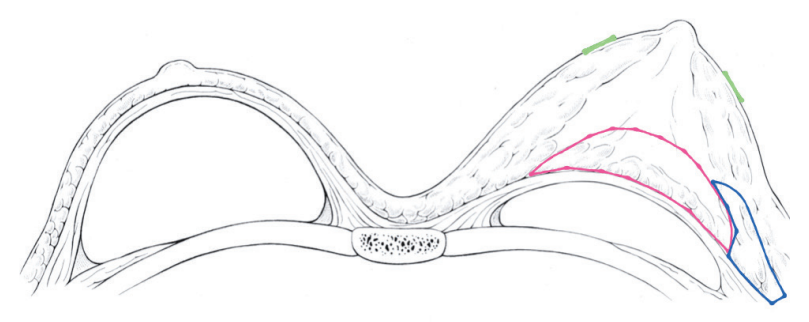

Fig. 3. Tailored mammaplasty along the breast sagittal axis

(A) An artist's drawing illustrates the sagittal axis of the breast during one-stage immediate breast reconstruction after nipple-sparing mastectomy. Notice that the breast conus (parenchyma) is completely replaced by the definitive anatomic implant that provides the shape and projection of the reconstructed breast. The conical projection of the healthy breast is lost. The implant-to-breast transition is rough, consisting of the implant covered by the pectoralis major, a thin layer of subcutis, and skin. (B) An artist's drawing shows the sagittal axis of the breast during a contralateral symmetrisation procedure. Notice that a smaller, low-projected implant has been placed in a dual-plane pocket to provide prosthetic imprinting to the contralateral breast. However, despite using the smallest implant possible, the augmentation mammaplasty alone cannot properly symmetrize the breast. The removal of the base of the breast (shown in pink), vertical/J-scar breast reduction (shown in yellow), and circumareolar skin removal (shown in green) are the steps of tailored reduction designed to properly symmetrize the breast by flattening the breast and nipple-areola complex and symmetrizing the base of the breast.
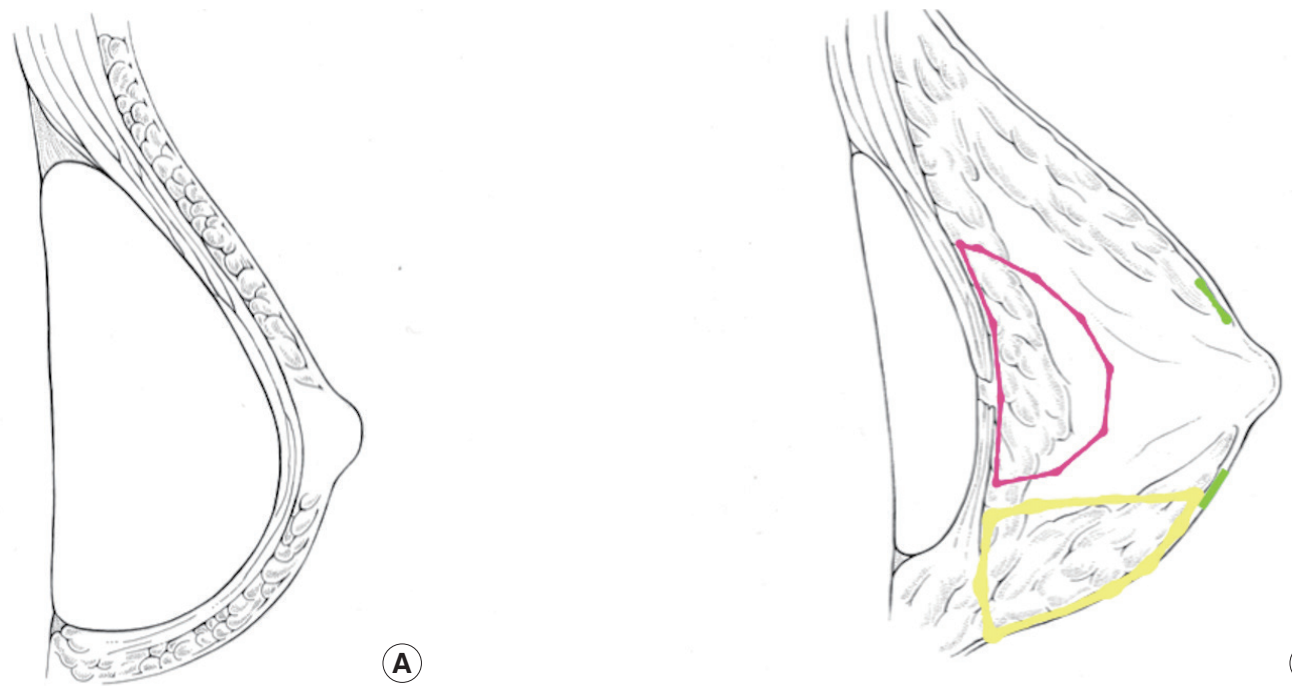

(B) 


\section{Fig. 4. A case of tailored mammaplasty}

(A) A preoperative picture of a 46-year-old left-breast cancer patient, for whom left nipple-sparing mastectomy, one-stage immediate reconstruction, and contralateral tailored reduction/augmentation mammaplasty were planned. Ptosis grade 2. (B) Two-month postoperative picture after left nipple-sparing mastectomy through a radial lazy S incision (mastectomy specimen $450 \mathrm{~g}$ ) and implant reconstruction with an Allergan Natrelle (Allergan Inc., Irvine, CA, USA) 410LX $570 \mathrm{~mL}$ implant and contralateral tailored reduction/augmentation mammaplasty with a J-scar pattern; dual-plane augmentation with an Allergan Natrelle 410ML $220 \mathrm{~g}$ implant; inferior pole, base, and superolateral quadrant tailored reduction (total specimen weight of $120 \mathrm{~g}$ ); and circumareolar skin resection with interlocking suture.
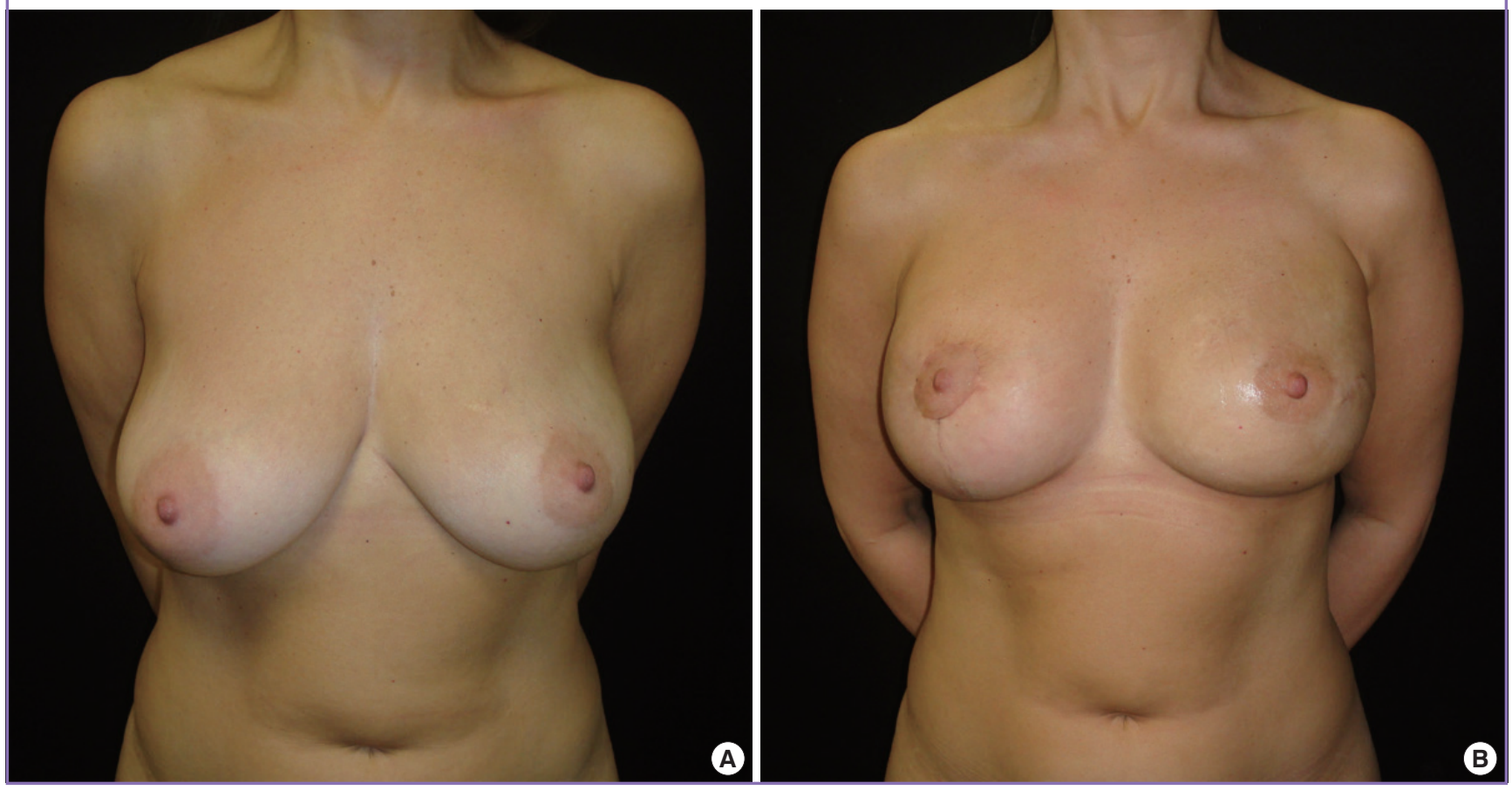

overall shape were assessed. After the resection, the patient was again placed into a semi-sitting position to check for symmetry. If the implant-to-breast transition was still unsatisfactory, further resections of the base and, eventually, of the lateral quadrants were performed. The extent of periareolar skin resection was determined based on the goal of flattening the breast and NAC, and CRIS was performed with the goal of matching the contralateral NAC size (Figs. 2, 3).

\section{RESULTS}

The average follow-up time was 13 months (range, 10-24 months). Seventeen of 19 patients did not require adjuvant chemoradiotherapy according to the final tumour pathology, whereas two patients underwent postoperative radiotherapy because of the presence of more than four metastatic axillary nodes.

No major complications, such as infection, haematoma, or NAC necrosis, were experienced on the healthy symmetrized breasts.

Patient satisfaction was high to very high in all patients. No secondary procedures were needed on the healthy symmetrized breasts (Figs. 4, 5).

\section{DISCUSSION}

In NSM, unlike in skin-sparing mastectomy, constraints due to NAC positioning and whole-skin envelope preservation strongly limit the use of skin redraping procedures over the implant. These factors also have a dramatic influence on the contralateral symmetrisation procedure.

On the NSM side, the absence of the adipoglandular breast conus is responsible for a rough implant-to-breast transition, consisting of muscle and skin. The breast takes the shape of the implant with regard to height, width, and projection as the skin shrinks over the muscle, adapting to the new breast conus. The absence of the adipoglandular component strongly influences both projection, resulting in a somewhat flat breast with a shrunken NAC that is smaller in diameter, and the overall shape, which is not conical but more bowl-like.

When dealing with contralateral healthy breast symmetrisation, if a durable symmetrisation is sought, it is always necessary to place an implant in order to provide prosthetic imprinting on the contralateral side. Unlike the mastectomy side, the implantto-breast transition on the healthy side is smoother because of the conus over the implant. This influences the height, width, 


\section{Fig. 5. A case of tailored mammaplasty}

(A, B) Preoperative pictures of a 45-year-old right-breast cancer patient for whom right nipple-sparing mastectomy, one-stage immediate reconstruction, and contralateral tailored reduction/augmentation mammaplasty were planned. No breast ptosis. (C, D) Three-month postoperative pictures after right nipple-sparing mastectomy through a radial lateral incision (mastectomy specimen $160 \mathrm{~g}$ ) and implant reconstruction with a Silimed hyper-projected anatomical implant (Nuance $350 \mathrm{~mL}$; Silimed International, Rio de Janeiro, Brazil). Contralateral tailored reduction/augmentation mammaplasty was performed via a periareolar scar, as well as dual-plane augmentation with an Allergan Natrelle $410 \mathrm{ML} 220 \mathrm{~g}$ (Allergan Inc., Irvine, CA, USA) implant, base reduction (specimen weight $35 \mathrm{~g}$ ), and circumareolar skin resection with interlocking suture.
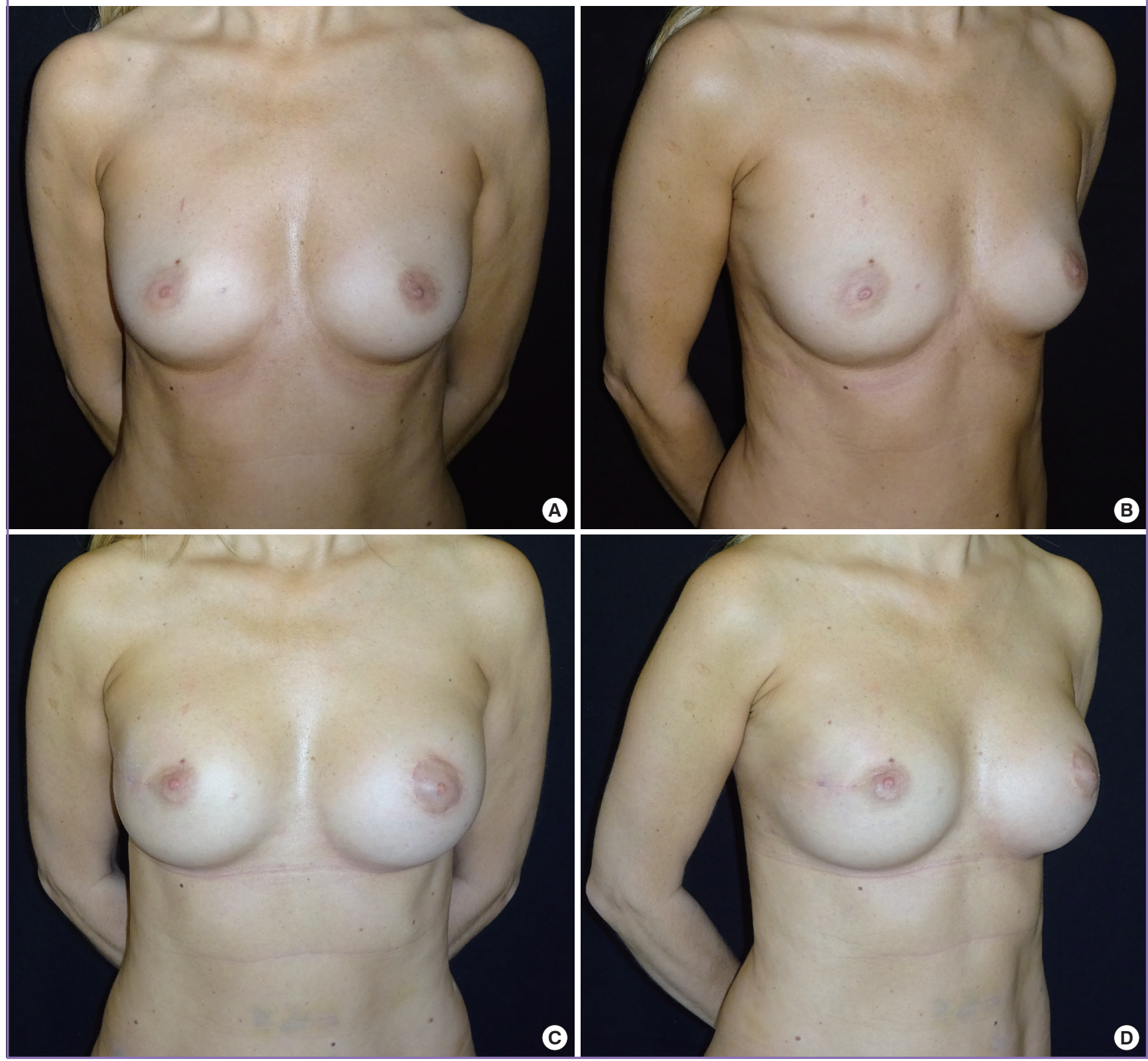

projection, and overall shape of the new breast.

In order to optimize the symmetrisation, the surgeon should shape the healthy breast in order to make it similar to the reconstructed side.

Breast width and height can be easily matched by choosing the proper low-projection anatomical implant based on preoperative breast asymmetry (if any) and the dimensions of the reconstructive implant, with the aid of sizers. However, the healthy breast always has a hyper-projected (conical) appearance and sometimes has a different overall shape.

Hyper-projection can be easily managed by combining two manoeuvres: the tailored resection of central breast base in order to directly reduce projection and CRIS in order to flatten the breast and to match NAC size.

When the overall shape is still different, as occurs in larger and ptotic breasts, a vertical-to-J-scar inferior quadrant resection as 
well as a lateral quadrant tailored resection can help adjust the shape of the breast.

In conclusion, based on our experience, simultaneous contralateral symmetrisation with a tailored reduction/augmentation mammaplasty after unilateral immediate implant reconstruction following NSM is a technique that helps achieve durable and pleasant symmetric outcomes.

\section{REFERENCES}

1. Endara M, Chen D, Verma K, et al. Breast reconstruction following nipple-sparing mastectomy: a systematic review of the literature with pooled analysis. Plast Reconstr Surg 2013; 132:1043-54.

2. Salgarello M, Visconti G, Barone-Adesi L. Nipple-sparing mastectomy with immediate implant reconstruction: cosmetic outcomes and technical refinements. Plast Reconstr Surg 2010;126:1460-71.

3. Spear SL, Shuck J, Hannan L, et al. Evaluating long-term outcomes following nipple-sparing mastectomy and reconstruction in the irradiated breast. Plast Reconstr Surg 2014; 133:605e-614e.

4. Losken A, Carlson GW, Bostwick J 3rd, et al. Trends in unilateral breast reconstruction and management of the contralateral breast: the Emory experience. Plast Reconstr Surg 2002;110:89-97.

5. Leone MS, Priano V, Franchelli S, et al. Factors affecting symmetrization of the contralateral breast: a 7-year unilateral postmastectomy breast reconstruction experience. Aes- thetic Plast Surg 2011;35:446-51.

6. Webster R. How does ptosis affect satisfaction after immediate reconstruction plus contralateral mammaplasty? Ann Plast Surg 2010;65:294-9.

7. Salgarello M, Visconti G, Barone-Adesi L. Dual-plane prosthetic reconstruction using the modified wise pattern mastectomy in women with macromastia. Plast Reconstr Surg 2011;127:1740-2.

8. Salgarello M, Visconti G, Barone-Adesi L, et al. Inverted-T skin-reducing mastectomy with immediate implant reconstruction using the submuscular-subfascial pocket. Plast Reconstr Surg 2012;130:31-41.

9. Salgarello M, Visconti G, Barone-Adesi L. One-stage immediate breast reconstruction with implants in conservative mastectomies [Internet]. Croatia: InTech; 2012 [cited 2014 Jan 27]. Available from: http://www.intechopen.com/books/ breast-reconstruction-current-techniques/one-stage-immediate-breast-reconstruction-with-implants-in-conservativemastectomies.

10. Davidenko JM, Pertsov AV, Salomonsz R, et al. Stationary and drifting spiral waves of excitation in isolated cardiac muscle. Nature 1992;355:349-51.

11. Salgarello M, Visconti G, Barone-Adesi L. Interlocking circumareolar suture with undyed polyamide thread: a personal experience. Aesthetic Plast Surg 2013;37:1061-2.

12. Gasperoni C, Salgarello M, Gasperoni P. A personal technique: mammaplasty with J scar. Ann Plast Surg 2002;48: 124-30. 